J. Lake Sci. (湖泊科学) , 2012, 24(6): 822-828

http: //www. jlakes.org. E-mail : jlakes@niglas.ac.cn

(C) 2012 by Journal of Lake Sciences

\title{
太湖湖滨带类型划分及生态修复模式研究"
}

\author{
叶 春, 李春华, 陈小刚, 焦向丽, 卢少勇 \\ (中国环境科学研究院湖泊工程技术中心, 环境基准与风险评估国家重点实验室,北京 100012)
}

\begin{abstract}
摘 要: 太湖湖滨带岸线总长 $405 \mathrm{~km}, 73 \%$ 以上被防洪大堤所包围, 其余部分临近山体, 属于典型的大堤型湖滨带. 按照 湖滨带地形地貌分为大堤型、山坡型、河口型三类, 根据水文条件和露滩情况, 又将大堤型分为长期露滩、间歇露滩、无滩 地型, 山坡型分为有滩地型、无滩地型, 形成 6 种类型的湖滨带. 根据以上太湖湖滨带划分类型, 结合湖滨带生境、气候、水 文条件以及植被分布现状等因素, 分别采取生态保育、生态修复、生态重建的对策, 设计了不同类型的太湖湖滨带生态修 复模式, 并分别提供了形象的修复模式示意图, 以期为太湖及其类似湖滨带的生态修复提供一定的借鉴.
\end{abstract}

关键词: 生态修复;湖滨带;分类;太湖

\section{Classification and ecological restoration modes for the littoral zone of Lake Taihu}

YE Chun, LI Chunhua, CHEN Xiaogang, JIAO Xiangli \& LU Shaoyong

(State Key Laboratory of Environmental Criteria and Risk Assessment, Centre of Lake Engineering and Technology, Chinese Research Academy of Environmental Sciences, Beijing 100012, P. R. China)

Abstract: The total length of littoral zone of Lake Taihu is about $405 \mathrm{~km}$, and more than $73 \%$ of which is surrounded by dike, other part is closed to hill. Therefore it is a typical dike-type littoral zone. According to different land forms, the littoral zone of Lake Taihu is classified as dike-type, hill-type and estuary-type. Based on the condition of hydrology and wetland area, the diketype is classified as 3 sub-types, namely, permanent-wetland-dike-type, intermittent-wetland-dike-type and non-wetland-diketype. The hill-type is classified as 2 sub-types, namely, wetland-hill-type and non-wetland-hill type. That means total 6 sub-types of littoral zones are defined in Lake Taihu. According to the above classification, several ecological restoration modes and their diagrams are proposed, which adopt different measures, from ecological conservation, ecological restoration to ecological reconstruction. The present research may have some implications for the ecological restoration of other lake littoral zones.

Keywords: Ecological restoration; littoral zone; classification; Lake Taihu

湖滨带是湖泊水体与陆地之间的过渡带, 属于生态交错带的一种, 也是湖泊生态系统的重要组成部分, 对维持湖泊生态系统的结构和功能起着积极作用 ${ }^{[1]}$. 然而我国自 $1970 \mathrm{~s}$ 来, 各地的围湖造田、环湖直立驳岸 的兴建、沿岸区域渔业养殖的超常规发展、旅游业的过度扩增, 侵占了大量湖滨湿地, 加速了湖滨带的生态 退化, 太湖、滇池、巢湖等大型湖泊的湖滨带无一例外地遭到了严重破坏 ${ }^{[24]}$. 湖滨带生态修复已经成为控制 湖泊富营养化的重要手段之一 ${ }^{[5-6]}$. 实践证明, 修复良好的湖滨带可显著提高湖泊水体的自净能力、促进生 物多样性恢复 ${ }^{[7-9]}$. 太湖是长江中下游五大淡水湖之一, 也是我国重点控制的 “三湖”之一, 对于太湖环境的 治理是目前的热点研究问题. 由于太湖湖滨带岸线较长, 湖滨带在地形地貌、风浪强度、生物现状、水位高 低、大堤位置等均有空间差异性, 因此, 在设计生态修复方案时, 需要对其进行不同类别的划分, 并按照不同 类别的湖滨带提出各自的生态修复模式. 虽有文献涉及湖滨带类型的划分 ${ }^{[10]}$, 但是对大堤型的湖滨带类型, 尚无阐述. 本文拟通过研究太湖湖滨带的特点, 进行湖滨带类型划分, 并按不同类型提出生态修复模式, 以 期对太湖及其他类似湖泊的生态修复有所借鉴.

* 国家水体污染控制与治理科技重大专项项目 (2009ZX07101-009) 资助. 2012-03-15 收稿;2012-05-21 收修改 稿. 叶春,男,1970 年生, 研究员;E-mail:yechbj@ 163. com. 


\section{1 太湖湖滨带特点及主要生态问题}

太湖湖滨带岸线总长 $405 \mathrm{~km}^{[11]}$, 根据本课题组 2010 年的测定, 梅梁湾段长 $76.2 \mathrm{~km}$, 竺山湾段长 $37.7 \mathrm{~km}$, 西部沿岸段长 $34.5 \mathrm{~km}$, 南部沿岸段长 $56.2 \mathrm{~km}$, 东太湖段长 $69.8 \mathrm{~km}$, 东部沿岸段长 $87.7 \mathrm{~km}$, 贡湖 段长 $43.2 \mathrm{~km}$. 与自然状态的湖滨带相比, 太湖湖滨带的物理构造有以下 3 大特点. (1) 典型的大堤型湖滨 带: 太湖湖滨带大部分被防洪大堤所包围, 其余部分临近山体, 属于典型的大堤型湖滨带. (2) 不涵盖陆向 辐射带: 由于湖滨带基本被环湖大堤及山体所包围, 原来的水陆物质交换也随之阻隔, 因此太湖湖滨带的范 围不再涵盖陆向辐射带. (3) 湖滨带范围窄: 根据对太湖湖滨带的水下地形、水文特征、植物群落分布考察, 将太湖湖滨带的范围界定为大堤以内 (水向) $50 \sim 100 \mathrm{~m}$ 的环形区域.

太湖湖滨带主要存在以下生态问题: (1) 生态脆弱性持续增加: 根据生态脆弱性综合评价结果, 太湖湖 滨带生态环境脆弱性状况在 1978 年最轻, 持续到 1991 年其状况均为轻脆弱性; 而从 1996-2008 年, 其生态 环境脆弱性指数呈现上升趋势, 2008 年已经达到强脆弱性 ${ }^{[12]}$. (2) 太湖湖滨带生态系统健康状况不容乐 观: 太湖湖滨带生态系统健康评价结果显示, 梅梁湾、竺山湾、西部沿岸的湖滨带均处于 “疾病” 状态; 南部沿 岸、东部沿岸、贡湖的湖滨带均处于 “亚健康” 状态; 只有东太湖湖滨带属于 “健康” 状态 ${ }^{[13]}$. (3) 人为活动是 太湖湖滨带生态系统健康状况的主要驱动因子: 运用统计分析方法识别的太湖湖滨带生态系统状态驱动因 子及驱动力大小排序为: 太湖主体营养状态 $>$ 堤岸类型 $>$ 人湖河流污染负荷通量 ${ }^{[14]} .3$ 个驱动因子均为负 面效应, 即太湖主体的营养状态综合指数越高、入湖河流污染负荷通量越大、大堤对湖滨带侵占越严重, 湖 滨带生态系统健康状态也就越差. 这 3 个驱动因子均与人为活动密切相关, 所以可以通过改善人类活动来 最终改善太湖湖滨带的生态系统健康状态. (4) 水生植物的分布受堤岸侵占以及风浪的影响: 以挺水植物 为例, 其面积由环湖大堤建造前的 $64.6 \mathrm{~km}^{2}$, 下降到 2008 年的 $6.38 \mathrm{~km}^{2}$, 缩小了近 $90 \%$; 在风浪较小的湖湾 区呈密集分布,而风浪较大的区域则只有零星分布.

\section{2 太湖湖滨带分类}

\section{1 湖滨带类型划分及定性描述}

湖滨带类型的划分是要揭示客观存在的湖滨带空间结构、生态过程和生态功能的差异, 为湖滨带分类 治理、生态恢复方案设计提供科学依据 ${ }^{[2]}$. 虽然太湖湖滨带组成复杂多样, 包括防洪大堤、露滩地、河口、山 前陡坡、鱼塘、水网养殖、水源保护点和景区等, 但是从湖滨带退化与生态恢复的工程角度, 可以按照特征分 类法进行分类, 主要从地形、地貌、水位水文等角度进行区 别 ${ }^{[15]}$. 根据太湖湖滨带地形地貌、水文条件的不同 以及与之相应的湖泊水生态系统的生态结构和湖泊使用功能的差异, 可建立针对太湖湖滨带的二级分类体 系. 首先按照湖滨带地形地貌进行一级分类, 类型有大堤型、山坡型、河口型. 其次根据水文条件和露滩情况 进行二级分类, 大堤型湖滨带可再次划分为长期露滩-大堤型、间歇露滩-大堤型、无滩地-大堤型, 山坡型湖 滨带也可再次划分为有滩地一山坡型、无滩地一山坡型.

2. 1.1 大堤型湖滨带 大堤型湖滨带, 顾名思义, 就是建有大堤的湖滨带类型. 按照太湖大堤和水位之间 的关系以及露滩面积大小, 又细分为长期露滩-大堤型、间歇露滩-大堤型、无滩地一大堤型 3 种 (图 $1 \mathrm{~A} 、 \mathrm{~B} 、$ C). (1) 长期露滩-大堤型: 是指湖滨带具有大堤, 且湖水在高水位时不能到达大堤堤脚, 因此大堤与水体 之间长期存在面积大小不等的露滩地. 该类型的湖滨带生态状态保持较好, 保留了自然湖滨带的基本特 点, 即由水域到岸边依次分布着沉水植物一浮叶植物-挺水植物一湿生植物. 此类型主要分布于东太湖、东 部沿岸、贡湖湖滨带. (2) 间歇露滩-大堤型 : 此类型特点是湖滨带具有大堤, 且湖水在高水位可以触及大堤 堤脚以上区域, 但是低水位时还不能达到大堤堤脚, 从而随着水位的变化在大堤与水体之间形成间歇性 的露滩. 此类型湖滨带由水域到岸边依次分布着沉水植物一浮叶植物-挺水植物, 但由于风浪对基底持续 淘蚀, 少有湿生植物生长. 此类型呈断续状分布于太湖湖滨带, 在竺山湾北部相对较多. (3) 无滩地一大 堤型: 湖滨带具有大堤, 且湖水在低水位就已经达到大堤的堤脚或以上部位, 因此大堤与水体间无滩 地存在, 风浪对基底有持续淘蚀, 只有少量沉水植物可以存活. 该类型湖滨带集中分布在西部沿岸和 南部沿岸。 


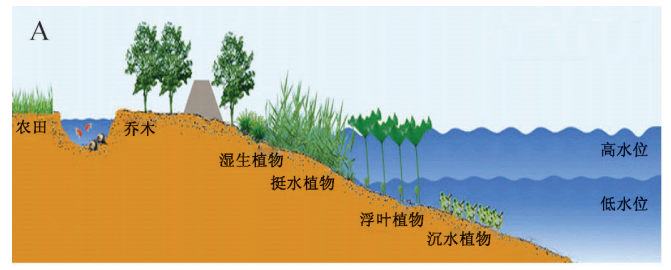

长期露滩一大堤型

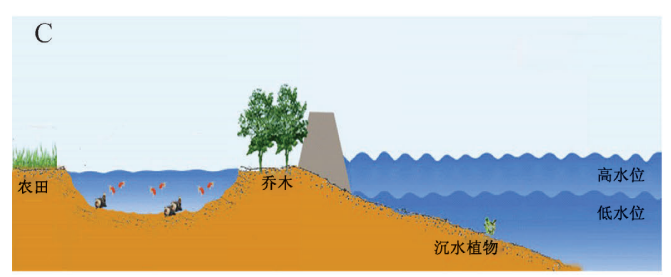

无滩地一大堤型

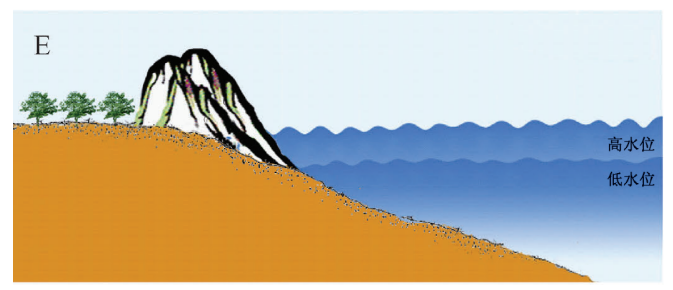

无滩地一山坡型

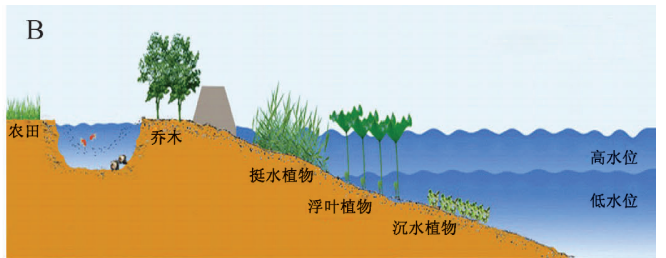

间歇露滩一大堤型

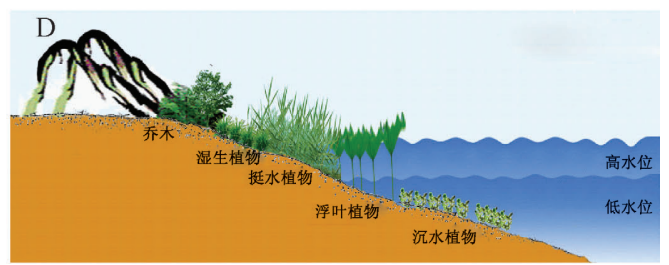

有滩地一山坡型

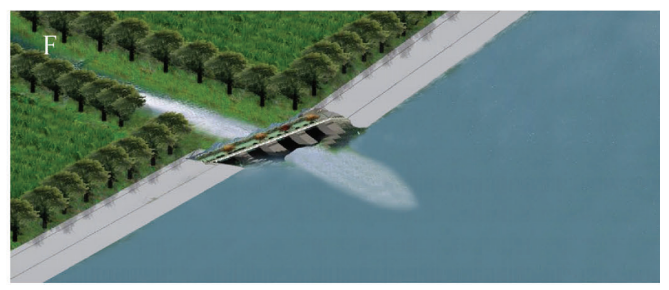

河口型

图 1 太湖湖滨带类型示意图

Fig. 1 Diagram of littoral zone types of Lake Taihu

2. 1.2 山坡型湖滨带 山坡型湖滨带是指湖滨带临近山体, 没有大堤围绕. 根据山体与湖泊水体之间有无滩 地等实地勘察, 又细分为有滩地一山坡型和无滩地一山坡型, (1) 有滩地一山坡型 (图 1D): 该类湖滨带的特点是 山体和湖泊水体有一定的距离, 由于湖水水位的变化在山体与水域之间形成滩地, 从水域到陆域依次分布 沉水植物-浮叶植物-挺水植物一湿生植物一灌乔木丛, 一般具有良好的生态环境. 滩地的类型大都是长期露 滩型. 此类型主要分布于梅梁湾湖滨带. (2) 无滩地一山坡型 (图 1E) : 此类湖滨带是指山体紧临湖水, 即湖水 在低水位时就已经到达山脚或以上部位, 因此山前无滩地存在, 故命名为无滩地一山坡型. 该种类型的湖滨 带很少有水生植物生长, 风浪长期淘蚀, 水土流失严重, 在竺山湾、梅梁湾、东部沿岸有零星分布.

2.1 .3 河口型湖滨带 河口型湖滨带 (图 $1 \mathrm{~F}$ ) 是河流的人、出湖口, 主要地貌特征为河口的边缘处有边滩, 前缘有心滩和浅滩, 形成复杂的滩地、水面镶嵌结构, 湿生、水生植物多样. 有些河流因输沙量较大, 泥沙 堆积在河口, 逐渐发育成河口三角洲湿地; 但有些河流基于人类通航及滨水环境利用的需要, 对河口进行 不同方式和程度的改造, 如河口滩地被开挖, 底质被疏浚, 有些河口处水深高达 $3.6 \mathrm{~m}$, 加上过往船舶以及 油污染的影响, 水生植被无法生存. 该类型湖滨带零星分布, 主要在太湖西北部、南部人湖河口、东部出湖 河口.

\section{2 湖滨带类型分布统计}

本课题组在 2009-2011 年不同季度对全太湖湖滨带进行了多次的实地勘察及核实, 完成了各类型湖滨 带的分布及长度统计, 各种类型的分布情况见图 2 , 但河口型由于相对长度太小, 难以在该图中显现. 各湖滨 带类型在不同区段的长度统计可以看出, 大堤型湖滨带共计 $297.80 \mathrm{~km}(99.36+98.02+100.42=297.80)$, 约占整个太湖岸线全长的 $73.6 \%$, 是太湖最主要的湖滨带类型, 在南部沿岸大堤型湖滨带占其总长度的 $96.4 \%$ 之高 (表 1). 大堤型的三种子类型的长度比较接近, 无滩地一大堤型湖滨带长度略长于长期露滩型及 间歇露滩型的. 山坡型湖滨带, 长度共计 $97.94 \mathrm{~km}$, 占岸线全长的 $24.2 \%$, 主要分布在东部沿岸、梅梁湾区 域, 其中有滩地一山坡型湖滨带长度大于无滩地一山坡型. 河口型长度共计 $9.17 \mathrm{~km}$, 占岸线全长 $2.3 \%$. 


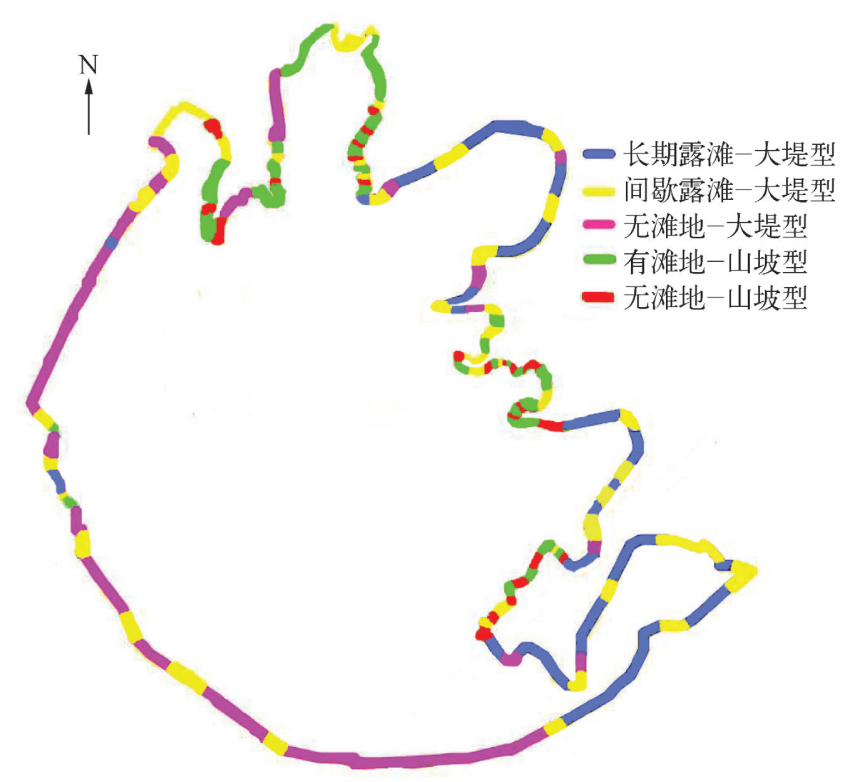

图 2 太湖不同类型湖滨带的分布情况

Fig. 2 Distribution of different types of littoral zones in Lake Taihu

表 1 湖滨带类型长度统计 $(\mathrm{km})$

Tab. 1 Length statistic results of different littoral zones

\begin{tabular}{lcccccc}
\hline 湖滨带区段 & 长期露滩-大堤型 间歇露滩-大堤型 & 无滩地-大堤型 & 有滩地-山坡型 & 无滩地一山坡型 & 河口型 \\
\hline 梅梁湾 & 0.87 & 16.00 & 16.87 & 34.53 & 7.16 & 0.82 \\
竺山湾 & 0 & 15.62 & 9.38 & 7.81 & 3.65 & 1.21 \\
西部沿岸 & 1.00 & 6.42 & 22.04 & 3.19 & 0 & 1.83 \\
南部沿岸 & 0 & 16.19 & 37.99 & 0 & 0 & 2.06 \\
东太湖 & 50.77 & 12.69 & 4.23 & 0 & 0 & 1.67 \\
东部沿岸 & 16.93 & 22.58 & 5.65 & 21.22 & 20.38 & 0.91 \\
贡湖 & 29.79 & 8.51 & 4.26 & 0 & 0 & 0.67 \\
共计 & 99.36 & 98.01 & 100.42 & 66.75 & 31.19 & 9.17 \\
\hline
\end{tabular}

\section{3 太湖湖滨带生态修复模式}

太湖湖滨带生态修复需以健康湖滨带微地貌景观结构为参照系, 充分考虑湖滨带在湖泊流域中的生态 环境功能和人类对湖滨带的利用, 根据以上太湖湖滨带划分类型, 结合湖滨带生境条件、具体气候、水文条 件以及植被分布现状等因素, 采用系统工程的思想和组合技术手段, 从生境条件修复以及生物恢复方面, 设 计不同类型的太湖湖滨带生态修复模式. 首先, 湖滨带生境条件的修复主要是从消浪、基底修复、藻类清除 三方面展开. 太湖沿岸风浪侵蚀严重, 对湖滨带生境条件的修复有重要影响, 需要在工程区内构建消浪效率 高、水位变化适应性强、生态景观协调性好、平面布局优、湖滨带与外界水体交换畅通的消浪结构, 使风浪对 湖滨带的冲刷和侵蚀大幅降低. 其次, 基底是生态系统发育与存在的载体, 良好的基底有利于保持湖滨带的 相对稳定, 缓解风浪、水流等不利水文条件对湖滨带生态恢复的影响. 再次, 藻类的堆积不仅产生黑臭水体、 危害其他生物的健康生长, 也会造成湖水流动不畅, 形成腐烂淤积物, 所以需要及时清理. 另外, 根据太湖湖 滨带生物调查, 其生物恢复应以挺水植物恢复为主, 兼顾大堤以内湿生、浮叶、沉水植物恢复, 引进底栖动 物等. 


\section{1 长期露滩-大堤型湖滨带生态修复模式}

该模式的修复要点是减少或去除区内围网养殖等人类活动; 以生态保育为主, 在植被稀疏的区域进行 植物扩增; 可作为大堤型湖滨带生态修复的参考类型. 该种类型湖滨带基本保持了原有湖滨带的滩地, 水生 植物生长状态较好, 因此基本不需要进行消浪措施; 基底修复采用 “基底保育模式”, 即仅需适当而少量的工 程措施, 增强基底稳定性, 为湖滨带的生态恢复和生态交错带的持续演替与发展创造条件. 该类型大堤与水 生态系统之间长期存在小片露滩地生态系统, 适合湿生植被的生长, 恢复措施主要是对堤防坡面进行草被 植物种植, 在露滩地系统的植被稀疏区域建设灌草湿生带, 防风固土, 涵养水源; 在核心区扩增挺水植物, 促 进浮叶、沉水植物恢复. 该类型的生态修复模式见图 $3 \mathrm{~A}$.

\section{2 间歇露滩 - 大堤型湖滨带生态修复模式}

该类型的生态修复要点是以生态修复为主, 恢复以挺水植物为主导的湖滨带生态系统; 改善区域内生 境条件, 控制风浪、修复基底, 在藻类堆积区还需要控制藻类堆积, 改善水环境, 修复湖滨生态. 此类型湖滨 带生态系统较脆弱, 由于风浪对基底持续淘蚀, 少有湿生植物生长. 所以建议在此类湖滨带离大堤堤脚 $50 \sim$ $80 \mathrm{~m}$ 区域设置木桩及进行局部基底地形改造, 以便消减风浪和改善水生植物生长基底环境. 生物恢复方面 主要恢复挺水植物为主导的湖滨带生态系统, 增加生物多样性. 具体而言, 大堤坡面应该考虑边坡的稳定、 绿化、过堤涵洞排放面源污水的处理, 在间歇露滩和人工堆积浅滩上进行耐湿灌木或草本植物恢复; 根据水 深及基底修复情况,引种挺水植物. 该类型的生态修复模式见图 3B.

\section{3 无滩地-大堤型湖滨带生态修复模式}

该模式的修复要点是以生态重建为主, 恢复以附着及底栖生物为主导的湖滨带生态系统; 条件允许的 地方可以参照间歇露滩-大堤型模式; 消能、消浪, 减弱驻波和回浪, 构建局部静水环境, 恢复附着和底栖生 物, 并有利于近岸浅水水域恢复沉水植物. 此类型特点是在低水位状态下, 水面达到大堤堤脚以上, 大堤前 无滩地存在, 风浪对基底持续淘蚀, 适合植物生长的露滩地也被淘蚀殆尽, 水生植被大面积消失. 根据此类 湖滨带特点, 在水深相对较深和风浪影响较大区域内, 在距离大堤堤脚 $80 \sim 100 \mathrm{~m}$ 用土工管袋充土作为潜 堤, 在潜堤外侧设置环保浮式消浪装置进行消浪; 水深相对较浅或风浪影响较小的区域, 可以采用木桩消浪 模式, 即在距离大堤堤脚 $80 \sim 100 \mathrm{~m}$ 设置木桩. 在堤脚边缘与中心区域内进行基底地形改造, 营造水生植物 生长的基底环境. 对风浪较大区域, 实施上述消浪、基底修复措施后, 构建局部静水环境, 等生物量恢复到一 定规模时, 再进行植物的恢复. 在前期挺水植物成功恢复后, 结合水质改善工程的实施, 在水体透明度成功 恢复到 $60 \sim 80 \mathrm{~cm}$ 左右时, 可以考虑在太湖水位高程 $2.5 \sim 2.7 \mathrm{~m}$ 范围内实施沉水植物恢复. 该类型的生态 修复模式见图 3 中的 $\mathrm{C}(1) 、 \mathrm{C}(2)$.

\section{4 有滩地一山坡型湖滨带生态修复模式}

该模式的修复要点是以生态保育为主, 恢复山坡与湖水之间的滩地生态系统; 去除或破坏局部硬质堤 岸, 消除人为干扰, 恢复滩地生境条件, 促进挺水植物扩增. 有滩地一山坡型湖滨带由于保持了原有湖滨带的 滩地, 水生植物生长状态较好, 因此基本不需要进行消浪措施, 基底修复也以生态保育为主. 该模式的植物 恢复遵从完全演替系列设计, 依据基底坡度和水位高程依次进行隔离防护带、乔灌草防护带建设, 人工扩增 挺水植物, 促进浮叶植物、沉水植物自然恢复, 挺水植物因地制宜或带状分布, 或交错块状分布. 在太湖水位 高程 $3.3 \sim 3.4 \mathrm{~m}$ 区域带内建立隔离防护带工程; 在太湖水位高程 $3.1 \sim 3.3 \mathrm{~m}$ 区域带内营造乔灌草防护带; 根据基底保育情况, 在太湖水位高程 $2.8 \sim 3.1 \mathrm{~m}$ 区域带内, 人工扩增挺水植物. 有滩地一山坡型湖滨带生态 修复模式见图 3D.

\section{5 无滩地-山坡型湖滨带生态修复模式}

该模式的修复要点是以生态保育为主, 这种模式人为干扰相对较小, 主要是来自湖泊水质的影响, 局部 措施没有多大作用, 以控制坡面水土流失和近岸陆生植被恢复为主. 由于无滩地一山坡型湖滨带水深较深, 人为干扰相对较少, 主要是来自湖泊水流的影响, 局部工程措施作用不明显, 以控制坡面水土流失和近岸陆 生植被恢复为主, 建议采用抛石消浪模式. 一方面可以消减风浪对近岸的淘刷、侵蚀, 另一方面可以减小水 流回流速度, 促使水中泥沙沉积, 在近岸区自然形成植物赖以生长的基底. 生物恢复措施包括在陆地系统建 设防护林或草林复合系统, 改善陆地环境, 在水域系统的水位变幅带及湖浪影响的范围内, 采用抛石消浪, 
适当引进沉水植物. 无滩地一山坡型湖滨带生态修复模式见图 3E.

\section{6 河口型湖滨带生态修复模式}

河口型的生态修复要点是恢复河口三角洲湿地, 利用配水措施和河口三角洲形态设计, 恢复湿地, 净化 人湖河流水质. 采取生物措施和物理工程措施相结合的方式, 并以生物措施为主, 以截留颗粒物和净化人湖 河流水质为主要功能,兼顾其它功能如改善河口景观, 增加生物多样性, 为鱼类产卵、育肥、受食提供栖息 地, 促进沉积、防止冲刷等. 河口湿地恢复还要考虑到不同河流的性质, 协调闸控、行洪、行船和正常径流净 化之间的关系. 河口型湖滨带生态修复模式见图 $3 \mathrm{~F}$.

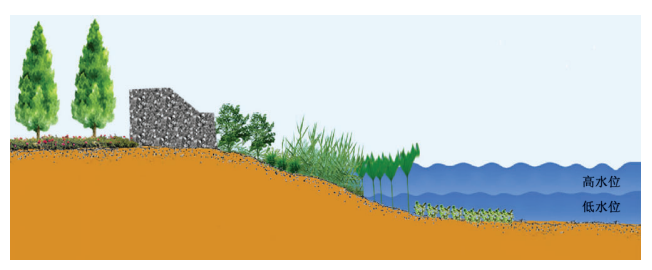

A : 长期露滩一大堤型

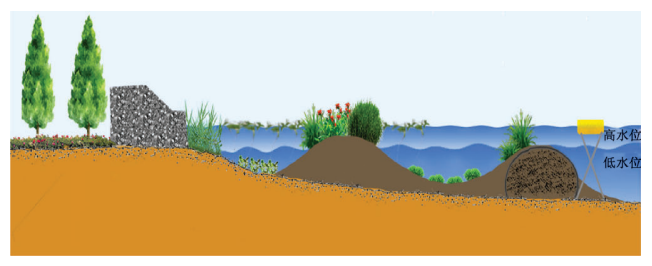

$\mathrm{C}(1)$ : 适合于水深或风浪大的无滩地一大堤型

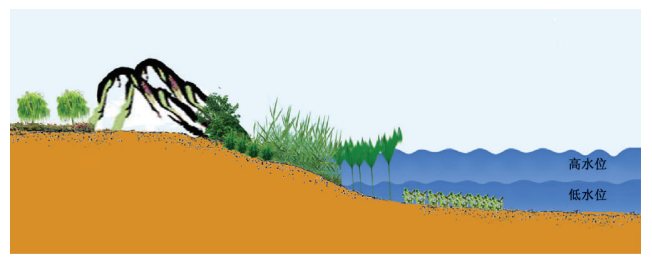

D: 有滩地一山坡型

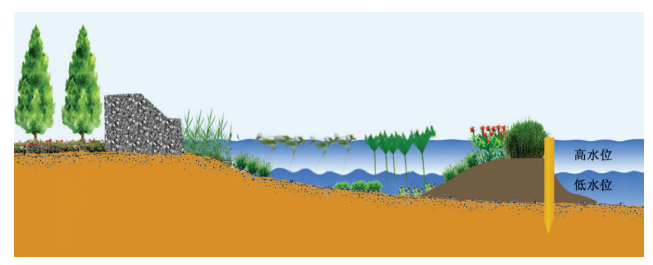

$\mathrm{B}$ : 间歇露滩一大堤型

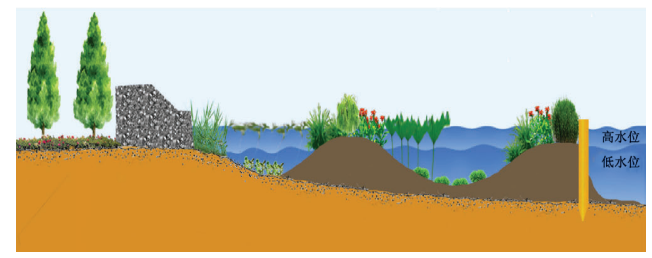

$\mathrm{C}(2)$ : 适合于水浅或风浪小的无滩地一大堤型

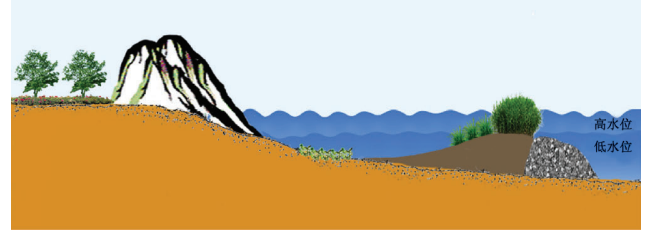

$\mathrm{E}$ : 无滩地一山坡型

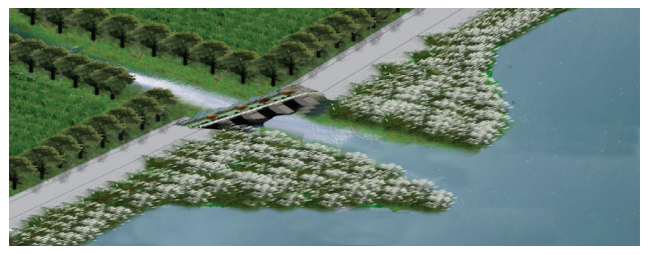

$\mathrm{F}$ : 河口型

图 3 太湖不同类型湖滨带的生态修复模式

Fig. 3 Ecological restoration mode for different littoral zone types of Lake Taihu

\section{4 结论}

1) 太湖湖滨带组成复杂多样, 本文从湖滨带退化与生态恢复的工程角度, 按照特征分类法, 建立了针对太 湖湖滨带的二级分类体系, 一级类型有大堤型、山坡型、河口型; 大堤型湖滨带的二级类型包括长期露滩-大堤 型、间歇露滩-大堤型、无滩地一大堤型, 山坡型湖滨带的二级类型为有滩地一山坡型、无滩地一山坡型.

2) 根据对全太湖湖滨带的实地勘察, 统计出了各种类型湖滨带的空间分布及长度. 大堤型湖滨带共计 $297.80 \mathrm{~km}$, 占整个太湖岸线全长的 $73.6 \%$, 是太湖最主要的湖滨带类型; 山坡型湖滨带, 长度共计 $97.94 \mathrm{~km}$, 占岸线全长的 $24.2 \%$; 河口型长度共计 $9.17 \mathrm{~km}$, 占岸线全长 $2.3 \%$. 
3) 根据不同太湖湖滨带划分类型, 结合湖滨带生境条件、具体气候、水文条件以及植被分布现状等因 素, 提出各种类型太湖湖滨带的生态修复模式. 其中长期露滩-大堤型、长期露滩一山坡型、无滩地一山坡型的 生态修复模式要以生态保育为主, 间歇露滩-大堤型要以生态修复为主, 而无滩地一大堤型的生态修复要点 是以生态重建为主, 河口型的生态修复要点是恢复河口三角洲湿地、净化人湖河流水质.

\section{5 参考文献}

[ 1 ] 叶 春. 退化湖滨带水生植物恢复技术及工程示范研究 [ 学位论文]. 上海: 上海交通大学, 2007.

[ 2 ] 叶 春,金相灿,王临清等. 洱海湖滨带生态修复设计原则与工程模式. 中国环境科学, 2004,24(6): 717-721.

[ 3 ] 秦伯强,胡维平, 陈伟民. 太湖水环境演化过程与机理. 北京: 科学出版社, 2004 .

[ 4 ] 许朋柱,秦伯强. 太湖湖滨带生态退化原因以及恢复与重建设想. 水资源保护, 2002,3:32-36.

[ 5] 金相灿. 湖泊富营养化控制和管理技术. 北京:化学工业出版社,2001.

[ 6 ] 王为东, 尹澄清,卢金伟等. 潜水丁坝在湖滨带生态恢复中的应用. 环境工程学报, 2007, (2):135-138.

[ 7 ] 尹澄清. 内陆水-陆地交错带的生态功能及其保护与开发前景. 生态学报, 1995, 15(3):331-335.

[ 8 ] 陈开宁,包先明,史龙新等. 太湖五里湖生态重建示范工程一大型围隔试验. 湖泊科学, 2006,18 (2): 139-149.

[ 9 ] Ye C, Li CH, Yu HC et al. Study on ecological restoration in near-shore zone of a eutrophic lake, Wuli Bay, Taihu Lake. Ecol Eng, 2011,39(9) : 1434-1437.

[10] 李英杰,金相灿, 胡社荣等. 湖滨带类型划分研究. 环境科学与技术, 2008,31(7):21-24.

[11] 孙顺才, 黄渏平. 太湖. 北京: 海洋出版社, 1993:3-9.

[12] 戈 锋, 叶 春, 冯冠宇等. 基于摘权综合健康指数法的太湖湖滨带水生态系统研究. 内蒙古师范大学学报: 自然 科学汉文版, $2010,39(6): 623-626$.

[13］李春华,叶 春,赵晓峰等. 太湖湖滨带生态系统健康评价研究. 生态学报, 2012,32(12):3806-3815.

[14] 叶 春, 李春华, 王秋光等. 大堤型湖滨带生态系统健康驱动因子一一太湖为例. 生态学报, 2012,32(12): 3681-3689.

[15] 黄民生,何 岩,方如康. 中国自然资源的开发、利用和保护: 第 2 版. 北京: 科学出版社,2011:93-100. 